\title{
The Translocator Protein
}

\author{
Alana M. Scarf ${ }^{1,2}$ and Michael Kassiou ${ }^{2-4}$ \\ ${ }^{I}$ Discipline of Pharmacology, University of Sydney, Camperdown, New South Wales, Australia; ${ }^{2}$ Brain and Mind Research Institute, \\ University of Sydney, Camperdown, New South Wales, Australia; ${ }^{3}$ School of Chemistry, University of Sydney, Camperdown, New \\ South Wales, Australia; and ${ }^{4}$ Discipline of Medical Radiation Sciences, University of Sydney, Camperdown, New South Wales, \\ Australia
}

The translocator protein (TSPO) is expressed at low levels in the healthy human brain and is markedly upregulated in response to brain injury and inflammation. This increase in TSPO expression is correlated to the extent of microglial activation, making the measurement of TSPO density a useful indicator of active brain disease. Several classes of TSPO radioligands have therefore been developed and evaluated for use in PET, to track the progression and severity of neuroinflammatory disease. TSPO is also overexpressed in cancer and peripheral inflammation, making TSPO PET ligands possible candidates for the imaging of a multitude of pathologies. However, we currently possess a limited understanding about the molecular structure of TSPO and about the interaction of ligands with the protein. Furthermore, the incomplete characterization of multiple TSPO binding sites and the role of TSPO polymerization suggest that current interpretation of PET data may require further refinement.

Key Words: translocator protein; microglia; PET; binding sites

J Nucl Med 2011; 52:677-680

DOI: 10.2967/jnumed.110.086629

The translocator protein (TSPO) has become an important target for imaging neuroinflammation using PET. TSPO is ubiquitously expressed in peripheral tissues but only minimally in the healthy human brain. Increased levels of TSPO expression have been noted in neuroinflammatory conditions such as Alzheimer disease, Parkinson disease, and stroke (1-3). This increase in TSPO expression has been reported to coincide with the process of microglial activation (2). Therefore, using high-affinity, selective TSPO ligands in conjunction with PET, it is possible to study the process of microglial activation in the living brain. Luus et al. (4) and Dolle et al. (5) offer more details on the development of TSPO radioligands for PET.

TSPO is also expressed in Schwann cells and macrophages of the peripheral nervous system, with increased expression in animal models of peripheral nerve injury (2)

Received Mar. 3, 2011; revision accepted Mar. 29, 2011.

For correspondence or reprints contact: Michael Kassiou, 100 Mallett St., Camperdown, New South Wales 2050, Australia.

E-mail: michael.kassiou@sydney.edu.au

COPYRIGHT @ 2011 by the Society of Nuclear Medicine, Inc. and macrophage activation (6). In fact, TSPO has been used in vitro to quantify plaque formation in a human model of atherosclerosis (6). Additionally, TSPO is significantly overexpressed in breast, prostate, colon, and brain cancer (7), with protein expression linked to cancer progression and poor survival rates (7), suggesting that the protein may be a useful marker in predicting cancer using PET. TSPO ligands have proved promising in preliminary studies for the quantitative assessment of human glioma (8) and in animal studies for imaging breast cancer (9). However, use of TSPO PET ligands for such applications is currently in preclinical stages and has not yet been fully utilized in human patients.

The TSPO is primarily situated at contact sites between inner and outer mitochondrial membranes and is part of the mitochondrial permeability transition pore (MPTP) (2). It interacts with various other proteins at the MPTP, including the $32-\mathrm{kDa}$ voltage-dependent ion channel and the $30-\mathrm{kDa}$ adenine nucleotide transporter, both of which are essential for the complex to become a functional unit (2). The protein is also found to a lesser extent in the cell nucleus and plasma membrane (2).

The TSPO is an $18-\mathrm{kDa}$ protein with 5 transmembrane domains (2). However, being a membrane-bound protein, the TSPO is a notoriously difficult target to study. Difficulties with expressing, purifying, and stabilizing the protein have hindered the determination of its X-ray crystal structure. Rather, researchers have attempted to elucidate the molecular structure using other approaches, such as thermodynamic simulations, immunodetection, nuclear magnetic resonance, and using the bacterial homolog, tryptophanrich sensory protein (TspO) from Rhodobacter sphaeroides (10). A 3-dimensional structure of TspO at $1-\mathrm{nm}(10-\AA)$ resolution has been determined (Fig. 1) using electron cryomicroscopy and single-particle helical reconstruction. Korkhov et al. (10) describe a pair of TspO monomers that form a tightly associated symmetric dimer in the membrane plane, with each monomer consisting of 5 transmembrane $\alpha$-helices. The authors suggest 2 binding sites per dimer, which allows for the possibility of cooperativity during substrate transport and potential effects of allosteric modulators. Although the exact functional significance of polymerization has not yet been confirmed, it has been 
FIGURE 1. (A) View perpendicular to membrane plane of TpsO dimer with $\alpha$-helices fitted into density. Yellow and blue $\alpha$-helices represent individual monomers of $\mathrm{TspO}$, and they are labeled arbitrarily $a-e$ and $a^{\prime}-e^{\prime}$. (B) View parallel to membrane plane of TspO dimer and after $40^{\circ}$ rotation to show highly tilted helices $e$ and $e^{\prime}$. (C) View perpendicular to membrane plane. (D) TspO monomer viewed parallel to membrane plane, from perspective of dimer interface formed by helices $a$ and $b$ and $a^{\prime}$ and $b^{\prime}$. (E) TspO monomer viewed from lipid bilayer. (Reprinted with permission of (10).)

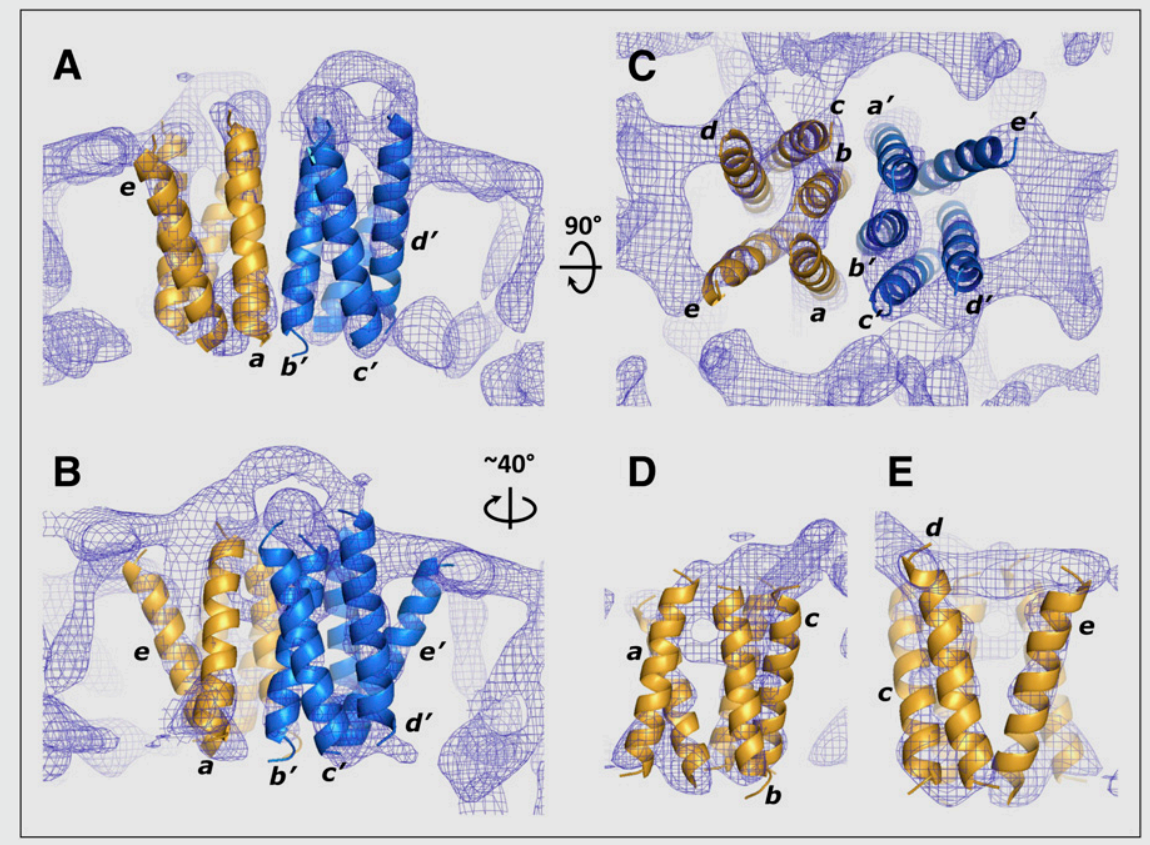

suggested that ligand binding and the onset of functional effects may be responsible for TSPO reorganization.

\section{TSPO FUNCTIONAL ROLES}

The best characterized function of TSPO is the regulation of cholesterol translocation through mitochondrial membranes, which is the rate-determining step in steroid biosynthesis (11). Once in the mitochondria, cholesterol is converted to pregnenolone via an oxidative cleavage of its side chain by cytochrome $\mathrm{P} 450_{\mathrm{SCC}}$ (2). TSPO ligands such as cholesterol are able to initiate steroidogenesis by binding to the protein.

The presence of TSPO at the MPTP also implicates the protein in the regulation of apoptotic and necrotic cell death, with ligands being able to cause opening of the MPTP, resulting in induction of apoptosis (11). TSPO ligands also inhibit cell proliferation in cancer cell lines, causing an accumulation of cells in the $G_{1} / G_{0}$ phase of the cell cycle, ultimately inhibiting the progression of cells to the $\mathrm{S}$ and $\mathrm{G}_{2} / \mathrm{M}$ phase, in which cell proliferation occurs (12). Effects on cell proliferation may be due to a small proportion of the protein being expressed within the cell nucleus. However, the effects of TSPO ligands on apoptosis and cell proliferation vary depending on ligand concentration, with antiproliferative and proapoptotic actions at micromolar concentrations but proproliferative effects through stimulation of mitosis and antiapoptotic effects at nanomolar concentrations $(11,13)$.

Because the TSPO is expressed on microglia and other immune cells, this protein also plays a role in immune regulation. Ligands that bind to TSPO are able to exert neuroprotective effects by modulating cytokine production $(1,2,14)$. However, whereas neuroprotective effects of
TSPO ligands are mediated at micromolar concentrations, more recent studies suggest that nanomolar concentrations mediate different functional profiles (14).

\section{TSPO BINDING SITES}

Although research suggests that there exist multiple TSPO binding sites, the nature of these sites and their functional significance is poorly understood. Two ligands have been essential for characterizing the TSPO: the benzodiazepine Ro 5-4864 and the isoquinoline carboxamide PK11195 (Fig. 2), both of which are selective for the TSPO and display nanomolar binding affinity. Although these ligands exhibit saturable binding and reciprocal competition in radioligand binding assays, results are not consistent across species and can be modified separately in both rats and humans (2). Furthermore, site-directed mutagenesis studies suggest certain residues in the first putative loop of TSPO are important for the binding of Ro 5-4864 but not PK11195. Thus, it is thought that PK11195 and Ro 54864 bind to heterogeneous sites at TSPO, either overlapping or allosterically coupled.

Studies also describe PK11195 binding to multiple sites, which contradicts the initial finding that it bound to a single population of saturable sites. Scatchard analysis of ${ }^{3} \mathrm{H}-$ PK11195 binding to Ehrlich tumor cells revealed 2 independent binding sites (13). Ehrlich tumor cells are a murine ascitic cell line, possessing high concentrations of polymeric TSPO. Alternatively, the induction of a high-affinity TSPO binding site may be related to an increase in steroid formation (15). Thus, it is possible that conformation of TSPO is altered to activate cholesterol delivery to the inner mitochondrial membrane. Considering that TSPO polymerization is associated with steroidogenesis, it is possible that 


\begin{tabular}{|c|c|c|c|c|c|c|c|}
\hline \multirow[t]{2}{*}{ Ligand } & \multirow[t]{2}{*}{ Structure } & \multicolumn{3}{|c|}{ Competition ${ }^{\star}$} & \multicolumn{3}{|c|}{ Saturation } \\
\hline & & $K_{i}(n M)^{\dagger}$ & Species & Ref & $K_{d}(n M)^{\dagger}$ & Species & Ref \\
\hline PK11195 & & $\begin{array}{r}3.0 \\
3.5 \pm 1.3 \\
4.4 \pm 0.5 \\
5.0 \\
4.5 \pm 0.4 \\
22.3 \pm 4.9\end{array}$ & $\begin{array}{l}\text { rat } \\
\text { rhesus } \\
\text { rhesus } \\
\text { human } \\
\text { human } \\
\text { human }\end{array}$ & $\begin{array}{l}(20) \\
(17) \\
(21) \\
(20) \\
(21) \\
(18)\end{array}$ & H) $\begin{array}{r}0.6 \pm 0.1 \\
\text { L) } 11.7 \pm 0.01 \\
2.3 \pm 0.9 \\
2.1 \pm 0.1 \\
28.5 \pm 14.4\end{array}$ & $\begin{array}{l}\text { rat } \\
\text { rat } \\
\text { human } \\
\text { human } \\
\text { human }\end{array}$ & $\begin{array}{l}(22) \\
(10) \\
(20) \\
(20) \\
(18)\end{array}$ \\
\hline Ro 5-4864 & & $\begin{array}{r}7.0 \\
750.0\end{array}$ & $\begin{array}{l}\text { rat } \\
\text { human }\end{array}$ & $\begin{array}{l}(20) \\
(20)\end{array}$ & $\begin{array}{r}7.3 \pm 0.8 \\
>>40\end{array}$ & $\begin{array}{l}\text { rat } \\
\text { human }\end{array}$ & $\begin{array}{l}(22) \\
(20)\end{array}$ \\
\hline PBR28 & & $\begin{array}{r}0.7 \pm 0.03 \\
0.6 \pm 0.3 \\
1.0 \pm 0.1 \\
2.5 \pm 0.4 \\
3.4 \pm 0.5 \\
2.9 \pm 0.3 \\
237 \pm 35 \\
3.4 \pm 0.1 \\
188 \pm 15.6 \\
\text { H) } 2.6 \pm 2 \\
\text { L) } 1404 \pm 803 \\
\text { H) } 4.0 \pm 2.4 \\
\text { L) } 313 \pm 17.6\end{array}$ & $\begin{array}{l}\text { rat } \\
\text { rhesus } \\
\text { rhesus } \\
\text { human } \\
\text { human } \\
\text { human } \\
\text { human } \\
\text { human } \\
\text { human } \\
\text { human } \\
\text { human }\end{array}$ & $\begin{array}{l}(21) \\
(17) \\
(21) \\
(21) \\
(18) \\
(19) \\
(19) \\
(18) \\
(18) \\
(19) \\
\\
(18)\end{array}$ & $\begin{array}{r}2.2 \pm 0.5 \\
52 \pm 23 \\
\text { H) } 1.3 \pm 0.2 \\
\text { L) } 135 \pm 161\end{array}$ & $\begin{array}{l}\text { human } \\
\text { human } \\
\text { human }\end{array}$ & $\begin{array}{l}\text { (18) } \\
\text { (18) } \\
\text { (18) }\end{array}$ \\
\hline DAA1106 & & $\begin{array}{r}0.07 \pm 0.01 \\
0.21 \\
0.2 \pm 0.01 \\
0.2 \pm 0.02 \\
2.8 \pm 0.4 \\
4.8 \pm 0.4 \\
13.1 \pm 1.3\end{array}$ & $\begin{array}{l}\text { rat } \\
\text { rhesus } \\
\text { rhesus } \\
\text { human } \\
\text { human } \\
\text { human } \\
\text { human }\end{array}$ & $\begin{array}{l}(21) \\
(17) \\
(21) \\
(21) \\
(19) \\
(19) \\
(19)\end{array}$ & $\begin{array}{r}0.1 \pm 0.03 \\
0.4 \pm 0.2 \\
0.4 \pm 0.04 \\
<1.0\end{array}$ & $\begin{array}{l}\text { rat } \\
\text { rat } \\
\text { resus } \\
\text { human }\end{array}$ & $\begin{array}{l}(23) \\
\text { (24) } \\
\text { (23) } \\
\text { (3) }\end{array}$ \\
\hline DPA-713 & & $\begin{array}{r}15 \pm 2.2 \\
26.8 \pm 2.9 \\
66.4 \pm 7.8\end{array}$ & $\begin{array}{l}\text { human } \\
\text { humann } \\
\text { human }\end{array}$ & $\begin{array}{l}(19) \\
(19) \\
(19)\end{array}$ & $1.3 \pm 0.2$ & mouse & (25) \\
\hline & & & & & & & \\
\hline
\end{tabular}

FIGURE 2. Saturation and competition binding profiles of various TSPO ligands using brain samples from different species in vitro. ${ }^{\star}$ Competition binding experiments conducted using ${ }^{3} \mathrm{H}-\mathrm{PK} 11195$ as radioligand. tWhere binding was bestfit to 2-site model using Scatchard analysis. $\mathrm{H}=$ high-affinity site; $\mathrm{L}=$ lowaffinity site. polymerization results in a conformational change to TSPO binding sites, potentially with allosteric effects.

More recently, studies in the human brain using various TSPO PET radioligands have revealed that TSPO binding sites vary across individuals and tissue type (16). For example, whereas ${ }^{3} \mathrm{H}$-PBR28 binds competitively to the ${ }^{3} \mathrm{H}-\mathrm{PK} 11195$ site in the brains of rhesus monkeys (17), ${ }^{3} \mathrm{H}-\mathrm{PBR} 28$ binds to multiple sites in postmortem human brains, with different affinities across a range of patients (Fig. 2) (18). Saturation data depict ${ }^{3} \mathrm{H}$-PBR28 binding to a low-affinity TSPO binding site, a high-affinity binding site, or a population of mixed-affinity binding sites, whereby data best fit a 2-site model (18). Conversely, ${ }^{3} \mathrm{H}-\mathrm{PK} 11195$ binds in the same manner in brain samples across all patients (18). Interestingly, however, differences in PK11195 binding across patients can be observed in some peripheral tissue (heart and lungs), correlating to the changes seen in the binding of PBR28 in brain (16). Since this discovery, several additional ligands that are commonly used for PET have been shown to display variable binding profiles across human subjects, with some ligands binding to multiple binding sites in select patients (Fig. 2) (19). This is despite the observation of a simple 1-site binding interaction when initially screened in the rat or rhesus monkey (Fig. 2).

It is possible that the variability in binding across human subjects could be a consequence of the level and nature of microglial activation, or the dose at which TSPO ligands are evaluated. Nevertheless, the concept of multiple TSPO binding sites and variable conformational states of the protein needs to be considered when developing and evaluating new PET TSPO ligands. This will aid in the development of adequate methods for quantitative analysis and a better understanding of what form of TSPO PET ligands are imaging.

\section{CONCLUSION}

Although the TSPO has been the focus of numerous studies for more than $30 \mathrm{y}$, its role in pathophysiology is still not completely understood. Efforts to elucidate the molecular nature of the TSPO in both health and disease 
have been hampered by several fundamental challenges unique to the TSPO as both a pharmacologic and an imaging target. We propose that this is due to a poor understanding of how ligands interact with the protein and a lack of knowledge about how the protein changes in disease states.

Microglial activation results in several changes that affect both the structure and the function of the TSPO. These changes include an increase in binding-site density, increased expression, and polymerization, which may result in complex ligand-binding interactions when compared with those found on resting microglia. These parameters may vary depending on the process of microglial activation, degree of microglial activation, and duration of microglial activation, which would vary across different disease states. This understanding of the TSPO is essential, irrespective of the imaging application-that is, neurologic versus oncologic. Therefore, the use of diverse animal models in the evaluation of new PET TSPO radioligands makes any comparison between ligands difficult. A more comprehensive understanding of how the TSPO behaves in disease states and how ligands interact with TSPO binding sites is required to enable the development of quantitative methods for PET data analysis that provide meaningful insights into the role of TSPO in the disease process.

\section{REFERENCES}

1. Rupprecht R, Papadopoulos V, Rammes G, et al. Translocator protein (18 kDa) (TSPO) as a therapeutic target for neurological and psychiatric disorders. Nat Rev Drug Discov. 2010;9:971-988.

2. Scarf AM, Ittner LM, Kassiou M. The translocator protein $(18 \mathrm{kDa})$ : central nervous system disease and drug design. J Med Chem. 2009;52:581-592.

3. Venneti S, Wang G, Nguyen J, Wiley C. The positron emission tomography ligand DAA1106 binds with high affinity to activated microglia in human neurological disorders. J Neuropathol Exp Neurol. 2008;67:1001-1010.

4. Luus C, Hanani R, Reynolds A, Kassiou M. The development of PET radioligands for imaging the translocator protein $(18 \mathrm{kDa})$ : what have we learned? $J$ Labelled Comp Rad. 2010;53:501-510.

5. Dolle F, Luus C, Reynolds A, Kassiou M. Radiolabelled molecules for imaging the translocator protein $(18 \mathrm{kDa})$ using positron emission tomography. Curr Med Chem. 2009;16:2899-2923.

6. Bird JLE, Izquierdo-Garcia D, Davies JR, et al. Evaluation of translocator protein quantification as a tool for characterising macrophage burden in human carotid atherosclerosis. Atherosclerosis. 2010;210:388-391.

7. Batarseh A, Papadopoulos V. Regulation of translocator protein $18 \mathrm{kDa}$ (TSPO) expression in health and disease states. Mol Cell Endocrinol. 2010;327:1-12.
8. Buck JR, McKinley ET, Hight MR, et al. Quantitative, preclinical PET of translocator protein expression in glioma using ${ }^{18} \mathrm{~F}-\mathrm{N}$-fluoroacetyl- $\mathrm{N}$-(2,5dimethoxybenzyl)-2-phenoxyaniline. J Nucl Med. 2011;52:107-114.

9. Wyatt S, Manning H, Bai M, et al. Molecular imaging of the translocator protein (TSPO) in a pre-clinical model of breast cancer. Mol Imaging Biol. 2010;12: 349-358.

10. Korkhov VM, Sachse C, Short JM, Tate CG. Three-dimensional structure of TspO by electron cryomicroscopy of helical crystals. Structure. 2010;18: 677-687.

11. Veenman L, Papadopoulos V, Gavish M. Channel-like functions of the $18 \mathrm{kDa}$ translocator protein (TSPO): regulation of apoptosis and steroidogenesis as part of the host-defense response. Curr Pharm Des. 2007;13:2385-2405.

12. Nahum R, Orit R, Svetlana L, et al. 7 Translocator protein $18 \mathrm{kDa}$ (TSPO) endogenous ligand affect metabolic activity and cell cycle of human osteoblastlike cell [abstract]. Mitochondrion. 2007;7:406.

13. Sakai M, Ferraz-de-Paula V, Pinheiro ML, et al. Translocator protein (18 kDa) mediates the pro-growth effects of diazepam on Ehrlich tumor cells in vivo. Eur J Pharmacol. 2010;626:131-138.

14. Choi Y, Lee MK, Lim SY, Sung SH, Kim YC. Inhibition of inducible NO synthase, cyclooxygenase-2 and interleukin-1B; by torilin is mediated by mitogen-activated protein kinases in microglial BV2 cells. $\mathrm{Br} J$ Pharmacol. 2009;156:933-940.

15. Papadopoulos V, Liu J, Culty M. Is there a mitochondrial signaling complex facilitating cholesterol import? Mol Cell Endocrinol. 2007;265-266:59-64.

16. Kreisl WC, Fujita M, Fujimura Y, et al. Comparison of $\left[{ }^{11} \mathrm{C}\right]-(\mathrm{R})-\mathrm{PK} 11195$ and $\left[{ }^{11} \mathrm{C}\right] \mathrm{PBR} 28$, two radioligands for translocator protein $(18 \mathrm{kDa})$ in human and monkey: Implications for positron emission tomographic imaging of this inflammation biomarker. Neuroimage. 2010;49:2924-2932.

17. Imaizumi M, Briard E, Zoghbi SS, et al. Brain and whole-body imaging in nonhuman primates of $\left[{ }^{11} \mathrm{C}\right] \mathrm{PBR} 28$, a promising PET radioligand for peripheral benzodiazepine receptors. Neuroimage. 2008;39:1289-1298.

18. Owen DR, Howell OW, Tang S-P, et al. Two binding sites for $\left[{ }^{3} \mathrm{H}\right] \mathrm{PBR} 28$ in human brain: implications for TSPO PET imaging of neuroinflammation. J Cereb Blood Flow Metab. 2010;30:1608-1618.

19. Owen DRJ, Gunn RN, Rabiner EA, et al. Mixed-affinity binding in humans with 18-kDa translocator protein ligands. J Nucl Med. 2011;52:24-32.

20. Awad M, Gavish M. Peripheral-type benzodiazepine receptors in human cerebral cortex, kidney, and colon. Life Sci. 1991;49:1155-1161.

21. Briard E, Zoghbi SS, Imaizumi M, et al. Synthesis and evaluation in monkey of two sensitive ${ }^{11} \mathrm{C}$-labeled aryloxyanilide ligands for imaging brain peripheral benzodiazepine receptors in vivo. J Med Chem. 2007;51:17-30.

22. Awad M, Gavish M. Binding of $\left[{ }^{3} \mathrm{H}\right]$ Ro 5-4864 and $\left[{ }^{3} \mathrm{H}\right] \mathrm{PK} 11195$ to cerebral cortex and peripheral tissues of various species: species differences and heterogeneity in peripheral benzodiazepine binding sites. J Neurochem. 1987;49:1407-1414.

23. Chaki S, Funakoshi T, Yoshikawa R, et al. Binding characteristics of $\left[{ }^{3} \mathrm{H}\right]$ DAA1106, a novel and selective ligand for peripheral benzodiazepine receptors. Eur J Pharmacol. 1999;371:197-204.

24. Venneti S, Lopresti BJ, Wang G, et al. A comparison of the high-affinity peripheral benzodiazepine receptor ligands DAA1106 and (R)-PK11195 in rat models of neuroinflammation: implications for PET imaging of microglial activation. J Neurochem. 2007;102:2118-2131.

25. Roberts JC, Friel SL, Roman S, et al. Autoradiographical imaging of PPAR [gamma] agonist effects on PBR/TSPO binding in TASTPM mice. Exp Neurol. 2009;216:459-470. 